\title{
Study of Condensed Phases, of Vaporization Temperatures of Aluminum Oxide and Aluminum, of Sublimation Temperature of Aluminum Nitride and Composition in an Air Aluminum Plasma
}

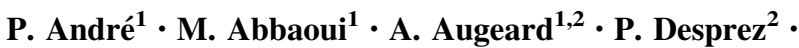 \\ T. Singo ${ }^{2}$
}

Received: 27 January 2016/ Accepted: 29 March 2016

(C) Springer Science+Business Media New York 2016

\begin{abstract}
With the Gibbs free energy method, we determine the molar fraction in a plasma at and out of thermal equilibrium consisting of air and aluminum for several percentages in the temperature range of 500-6000 K. We take three temperatures into account $\left(T_{r o t}=T_{h} ; T_{v i b} ; T_{e x}=T_{e}\right)$. We indicate the formulae and the numerical method used to perform the calculation taking three condensed phases $\mathrm{AlN}, \mathrm{Al}, \mathrm{Al}_{2} \mathrm{O}_{3}$ into account. We show that the air percentage plays a major role to create these phases. We clarify the role plays on the vaporization temperatures and on the sublimation temperature by the non-thermal equilibrium of the plasma. This kind of plasma is found in arc roots, near a wall, in plasmas with a high value of electrical field,... The influence of the pressures until $30 \times 10^{5} \mathrm{~Pa}$. is shown on molar fraction of the chemical species, on the vaporization temperatures and on the sublimation temperature. The vaporization temperatures are given versus the thermal non equilibrium versus various mixtures (air, aluminum) and versus the pressures $\left(10^{5} \mathrm{~Pa}-30 \times 10^{5} \mathrm{~Pa}\right)$.
\end{abstract}

Keywords Aluminum nitride $\cdot$ Aluminum oxide $\cdot$ Aluminum $\cdot$ Plasma $\cdot$ Vaporization temperature $\cdot$ Sublimation temperature $\cdot$ Chemical equilibrium $\cdot$ Multitemperature plasma

PACS Nos. 52.27.Cm $\cdot$ 52.77.-j $\cdot$ 64.70.fm $\cdot$ 64.75.-g

P. André

pascal.andre@univ-bpclermont.fr

1 LAEPT, EA4646, Université Clermont Auvergne, 4 av Blaise Pascal, 63178 Aubière Cedex, France

2 Direction de la Recherche, SAFT, 111/113, Boulevard Alfred Daney, 33074 Bordeaux Cedex, France 


\section{Introduction}

In several set-ups, such as in plasma ignition technology [1], in arc tracking [2], for Current Interrupt Device (CID) inside elements of lithium-ion battery [3], for the arc welding [4] ... the electrodes and the wires are made of aluminum. During the process, the interaction of air and aluminum plays a key role. Furthermore the electrical field can reach very high value that can lead the plasma to be out of thermal equilibrium (the electrons get a higher temperature than the one of heavy species). At low temperatures, the condensed phases can be conductive or insulating and then have a major influence on the electrical circuits. During the work of the set up the variation of air proportion can appear and the pressure can vary.

To model such plasmas the interaction between electrical arc and the material surface is a key parameter to improve Computational Fluid Dynamic (CFD) calculation codes [5]. To describe the arc roots, we have to know the electronic flux for example thermionic electron emission flux. This latter depends on the surface temperature of the electric contacts [6]. Thus the sublimation temperature or the vaporization temperature are fundamental to knowing when the solid sublimates or liquid vaporizes. This is used in CFD code to test when the mesh of solid or of liquid has to be replaced by a gas or plasma [7]. Furthermore, it is well known that close to the cathodic surface or close to a sheath the plasma is out of thermal equilibrium due to high electrical field or to diffusion [8]. To model these areas one has to answer to the question: are the vaporization and sublimation temperatures of the metal a function of the degree of thermal non-equilibrium?

So, the purpose of the paper is to show the influence of the air proportion, the thermal non-equilibrium and the pressures on the chemical processes, notably the condensed phases. These latter can be created after extinguishing of the electric default (electric arc, spark, hot gas...). We show that the vaporization temperatures of $\mathrm{Al}_{2} \mathrm{O}_{3}$ and $\mathrm{Al}$ as well as the sublimation temperature of AlN depends on the considered physical constraints.

In a first part, we depict the needed data, the physical formulae and the numerical method. In a second part, we determine the molar fraction in the temperature range of $500-6000 \mathrm{~K}$ versus proportion of air and aluminum at thermal equilibrium and at $10^{5} \mathrm{~Pa}$. In a third part, we determine molar fraction with a plasma out of thermal equilibrium. For the internal temperatures, the rotational temperature $T_{r o t}$ is assumed to be closed to the translational temperature of heavy species $T_{h}$, the excitational temperature $T_{e x}$ closed to the translational temperature of electrons $T_{e}$ and vibrational temperature $T_{v i b}$ is assumed to be

intermediate between $T_{e}$ and $T_{h}$ as $T_{v i b}=\sqrt{\theta} T_{h}$. The considered heavy species temperature are included between $500 \mathrm{~K}$ and $6000 \mathrm{~K}$. The calculation are made for a mixture of $10 \%$ of air and $90 \%$ of aluminum, for a mixture of $50 \%$ of air and $50 \%$ of aluminum and for a mixture of $90 \%$ of air and $10 \%$ of aluminum. The vaporization temperatures and sublimation temperature are studied versus the non-thermal parameter $\theta=\frac{T e}{T_{h}}$. In a third part, we study the influence of pressure between $10^{5} \mathrm{~Pa}$ until $30 \times 10^{5} \mathrm{~Pa}$.

\section{First Step Determination of Liquid Phase and Solid Phase}

The dry air composition is that given by the US Standard: $\mathrm{N}_{2} 78.084 \% ; \mathrm{O}_{2} 20.9476 \%$; Ar $0.934 \% ; \mathrm{CO}_{2} 0.0314 \%$ in molar percentage [9]. In the calculation we take into account the Aluminium oxide $\mathrm{Al}_{2} \mathrm{O}_{3}$ in solid phase in which we do not distinguish the various phase $(\alpha, \delta, \gamma \ldots)$, the liquid phase of Aluminium oxide, the aluminium nitride in solid 
phase and the aluminum in solid and liquid phases. The liquefaction temperature of $\mathrm{Al}_{2} \mathrm{O}_{3}$ is taken equal to $2327 \mathrm{~K} \mathrm{[10],} \mathrm{the} \mathrm{liquefaction} \mathrm{temperature} \mathrm{of} \mathrm{aluminum} \mathrm{is} \mathrm{taken} \mathrm{equal} \mathrm{to}$ 933.45 K [10]. The liquid is considered to be an ideal liquid and Van der Waals interactions are neglected. The condensed phases are immiscible. We take 13 monatomic species into account: $\mathrm{Al}, \mathrm{Al}^{-}, \mathrm{Al}^{+}, \mathrm{Ar}, \mathrm{Ar}^{+}, \mathrm{C}, \mathrm{C}^{-}, \mathrm{C}^{+}, \mathrm{N}, \mathrm{N}^{+}, \mathrm{O}, \mathrm{O}^{-}$, and $\mathrm{O}^{+}, 23$ diatomic species $\mathrm{Al}_{2}, \mathrm{AlN}, \mathrm{AlO}, \mathrm{AlO}^{-}, \mathrm{AlO}^{+}, \mathrm{C}_{2}, \mathrm{C}_{2}{ }^{-}, \mathrm{C}_{2}{ }^{+}, \mathrm{CN}, \mathrm{CN}^{-}, \mathrm{CN}^{+}, \mathrm{CO}, \mathrm{CO}^{-}$, $\mathrm{CO}^{+}, \mathrm{N}_{2}, \mathrm{~N}_{2}{ }^{-}, \mathrm{N}_{2}{ }^{+}, \mathrm{NO}, \mathrm{NO}^{-}, \mathrm{NO}^{+}, \mathrm{O}_{2}, \mathrm{O}_{2}{ }^{-}, \mathrm{O}_{2}{ }^{+}, 31$ polyatomic species $\mathrm{Al}_{2} \mathrm{O}, \mathrm{Al}_{2} \mathrm{O}_{2}$, $\mathrm{Al}_{2} \mathrm{O}_{2}{ }^{+}, \mathrm{Al}_{2} \mathrm{O}^{+}, \mathrm{AlO}_{2}, \mathrm{AlO}_{2}{ }^{-}, \mathrm{C}_{2} \mathrm{~N}, \mathrm{C}_{2} \mathrm{~N}_{2}, \mathrm{C}_{2} \mathrm{O}, \mathrm{C}_{3}, \mathrm{C}_{3} \mathrm{O}_{2}, \mathrm{C}_{4}, \mathrm{C}_{4} \mathrm{~N}_{2}, \mathrm{C}_{5}, \mathrm{CNN}, \mathrm{CNO}, \mathrm{CO}_{2}$, $\mathrm{CO}_{2}{ }^{-}, \mathrm{N}_{2} \mathrm{O}, \mathrm{N}_{2} \mathrm{O}_{3}, \mathrm{~N}_{2} \mathrm{O}_{4}, \mathrm{~N}_{2} \mathrm{O}_{5}, \mathrm{~N}_{2} \mathrm{O}^{+}, \mathrm{N}_{3}, \mathrm{NCN}, \mathrm{NO}_{2}, \mathrm{NO}_{2}{ }^{-}, \mathrm{NO}_{3}, \mathrm{O}_{3}, \mathrm{NO}_{3}{ }^{-}, \mathrm{CO}_{2}{ }^{+}$and electrons.

In multitemperature plasmas, following the Boltzmann distribution from populated quantum levels, one can define several kinds of temperatures: vibrational, excitational, rotational and translational. We assume that the rotational temperature, vibrational temperature, excitational temperature are the same for all the diatomic species and the excitational temperature are the same both for monatomic species and diatomic species. We assume that for all the heavy chemical species, neutral and ionic, translational temperatures have the same value. So, the translational temperatures of heavy species are the same for all kind of species omitting electrons. Usually the rotational temperature is assume to be closed to the translational temperature of heavy species and the temperature of excitational temperature closed to the translational temperature of electrons. The measurements made in several set-ups [11-13] show that the vibrational temperature is intermediate between the heavy species temperature and electronic temperature so we choose the following assumption on the temperatures:

$$
\left\{\begin{array}{l}
T_{h}=T_{r o t} \\
T_{e}=T_{e x}=\theta T_{h} \\
T_{v i b}=\sqrt{\theta} T_{h}
\end{array}\right.
$$

For all considered chemical species, the translational partition function is written as:

$$
z_{t r}=\left(\frac{2 \pi m_{i} k T_{t r}}{h^{2}}\right)^{3 / 2} \frac{k T_{t r}}{P^{0}}
$$

where $k$ is the Boltzmann constant, $h$ the Planck constant, $m_{i}$ the mass of the $i$ chemical species, $P^{O}$ the standard pressure $\left(10^{5} \mathrm{~Pa}\right)$ and $T_{t r}$ equal to $T_{e}$ for electrons and to $T_{h}$ for heavy species.

We take into account for the monatomic species, the internal partition function written as [14]:

$$
z_{\text {int }}=\sum_{n, l, s} g(n, l, s) e^{-E(n, l, s) / T_{e x}}
$$

where $g(n, l, s)$ and $E(n, l, s)$ are respectively the degeneracy and energy of the state with principal quantum number $n$, azimuthal quantum number $l$ and spin $s$ [15]. To increase the accuracy of the partition function at high temperatures, some authors [16] add levels with the help of the Ritz-Rygdberg series. Due to our temperature range between 500 and $6000 \mathrm{~K}$ only the low energy levels are populated [14] so we considered only the levels given in literature.

For the diatomic molecules, the treatment is the one given by Drellishak and al [17] at the thermal equilibrium. Then the internal partition function is written as: 


$$
z_{\text {int }}=\sum_{n=1}^{n_{\max }} g_{n} e^{-L T_{e}(n) / T} \sum_{v=0}^{v_{\max }(n)} e^{-L G(n, v) / T} \sum_{J=0}^{J \max (n, v)} \frac{(2 J+1)}{\sigma} e^{-L F(n, v, J) / T}
$$

where $J$ is the rotational quantum number; $F(n, v, J)$ is the rotational spectral term depending on the vibrational quantum $v$ and on the electronic state $n ; G(n, v)$ is the vibrational spectral term depending on the electronic state $n ; T_{e}(n)$ the electronic spectral term of the electronic quantum state, $g_{n}$ is the statistical weight of the electronic sate; $\sigma$ is a

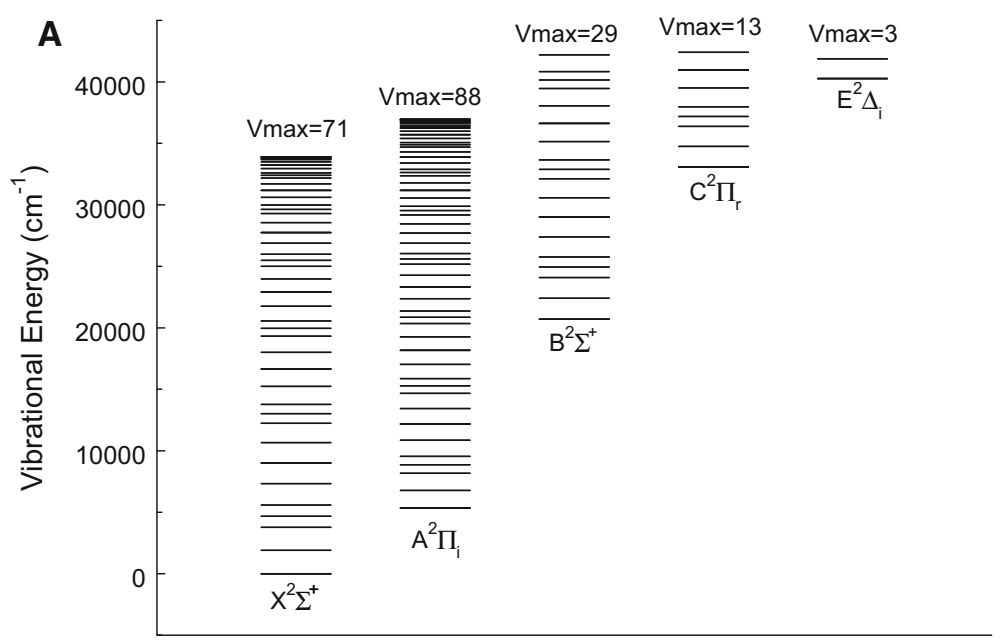

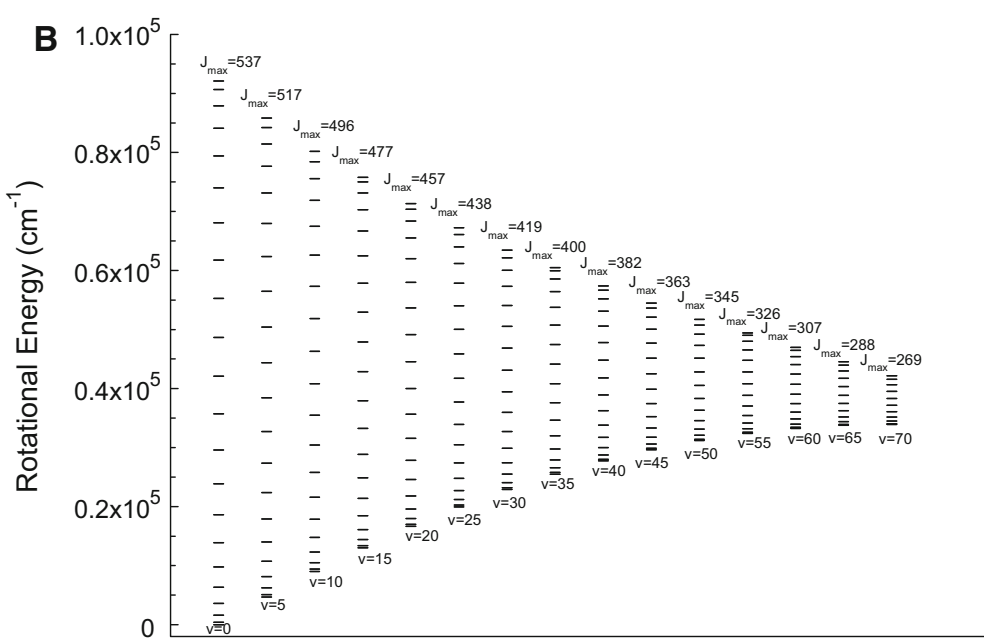

Fig. 1 a A representation of the vibrational levels versus electronic states taken into account for the partition function calculation of AlO. We only indicate the energies of vibration quantum multiple of 5. b A representation of the rotational levels versus the vibrational quantum number (multiple of 5) of the fundamental electronic state $X^{2} \Sigma^{+}$of AlO. We only indicate the rotational energies of rotational quantum number multiple of 25 
symmetry factor equal to 1 when the two atoms are different and equal to 2 when the atoms are identical.

To get the partition functions in non-thermal plasmas we separate artificially the electronic, vibrational and rotational levels as in [18] and [19]:

$$
z_{\text {int }}=\left(\sum_{n=1}^{n_{\max }} g_{n} e^{-\frac{L T_{e}(n)}{T_{e x}}}\right)\left(\sum_{v=0}^{v_{\max (\mathrm{n}=1)}} e^{-\frac{L G(1, v)}{T_{v i b}}}\right)\left(\sum_{J=0}^{J \max (n=1, v=0)} \frac{(2 J+1)}{\sigma} e^{-\frac{L F(1,0, J)}{T_{r o t}}}\right)=Z_{e x} Z_{v i b} Z_{r o t}
$$

With $Z_{e x}$ the electronic partition function, $Z_{v i b}$ the vibrational partition function and $Z_{\text {rot }}$ rotational partition function. That is to say, in the calculation of diatomic partition function for example AlO we only take into account the levels of the first columns of Fig. 1a, b.

The chemical potential for monatomic species is written as:

$$
\mu_{\text {monat }}^{0}=-k T_{\text {ex }} \ln \left(Z_{\text {int }}\right)-k T_{\text {tr }} \ln \left(Z_{\text {tr }}\right)+e^{0}
$$

With $e_{0}$ is the formation enthalpy of the considered chemical species.

Obviously the electronic excitation temperature and translational temperature are identical at thermal equilibrium.

The chemical species for diatomic species is written as:

- At thermal equilibrium all the temperatures are identical:

$$
\mu_{\text {diat }}^{0}=-k T \ln \left(Z_{\text {int }}\right)-k T \ln \left(Z_{\text {tr }}\right)+e^{0}
$$

- And out of thermal equilibrium:

$$
\mu_{\text {diat }}^{0}=-k T_{e x} \ln \left(Z_{e x}\right)-k T_{\text {vib }} \ln \left(Z_{\text {vib }}\right)-k T_{\text {rot }} \ln \left(Z_{r o t}\right)-k T_{t h} \ln \left(Z_{t r}\right)+e^{0}
$$

For the polyatomic chemical species and the condensed chemical species we take the chemical potential and the enthalpy formation in [10]. We assumed that the main constraint on the plasma properties is due to the pressure then we used the Gibbs free energy minimisation out of thermal equilibrium [20, 21]. So, the Gibbs energy of the system can be divided in three terms:

- The electrons contribution:

$$
G_{e}=n_{e}\left[\mu_{e}^{0}+k T_{e} \ln \left(\frac{T_{e} n_{e}}{T_{e} n_{e}+T_{h} \sum_{i=1 ; i \neq e}^{N_{p g}} n_{i}}\right)+k T_{e} \ln \left(\frac{P}{P^{0}}\right)\right]
$$

- The gaseous heavy species contribution:

$$
G_{p g \_i}=\sum_{i=1}^{N_{p g}} n_{i}\left[\mu_{i}^{0}+k T_{h} \ln \left(\frac{T_{h} n_{i}}{T_{e} n_{e}+T_{h} \sum_{i=1 ; i \neq e}^{N_{p g}} n_{i}}\right)+k T_{h} \ln \left(\frac{P}{P^{0}}\right)\right]
$$

- The liquid and solid species contribution:

$$
G_{l s}=\sum_{i=1}^{N_{l s}} n_{i} \mu_{i}^{0}
$$


Several numerical methods have been developed in the case of complex chemical equilibrium compositions [22], we have to modify the numerical method given in [23] and [24] to take into account all the condensed phases and the non-thermal equilibrium.

\section{Influence of the Air Proportion}

To depict the influence of air on the formation of condensed phases, we have chosen several proportions of air with pure aluminum. In Table 1, we give the vaporization temperatures $\left(\mathrm{Al}_{2} \mathrm{O}_{3}, \mathrm{Al}\right)$ and sublimation temperatures $(\mathrm{AlN})$ of nine mixtures and in Fig. 2 we have plotted the molar fractions for five featured and interesting mixtures.

In Fig. 2a, we have plotted the molar fraction of chemical species versus temperature for a mixture of pure aluminum at $90 \%$ and in dry standard air at $10 \%$ in molar percentage at $10^{5} \mathrm{~Pa}$. The main condensed chemical species is the aluminum in solid phase below $933 \mathrm{~K}$ and in liquid phase between this latter temperature and $2767 \mathrm{~K}$. The second main condensed phase is the aluminum nitride that sublimate around $2682 \mathrm{~K}$. The third main condensed phase is the aluminum oxide that is in solid phase below $2327 \mathrm{~K}$ and liquid until its vaporization around $2387 \mathrm{~K}$. The argon is an inert gas. It does not react with other chemical species. The argon is the main gaseous chemical species at the lower temperature. After the $\mathrm{Al}_{2} \mathrm{O}_{3}$ vaporization and before the AlN sublimation, the main gaseous species is the gaseous aluminum oxide $\left(\mathrm{Al}_{2} \mathrm{O}\right)$. Then the Nitrogen is the main gaseous chemical species until the vaporization of aluminum. For the higher temperature gaseous aluminum is the main chemical gaseous species. Indeed, the ionization energy of $\mathrm{Al}_{2} \mathrm{O}$ is $8.2 \mathrm{eV}$ is lower than the ionization energy of the main gaseous molecule $\mathrm{N}_{2}$ $(15.58 \mathrm{eV})$ and it is higher than the dissociation energy of $\mathrm{Al}_{2}(2.73 \mathrm{eV})$. To compare the $\mathrm{Al}_{2} \mathrm{O}^{+}$and $\mathrm{Al}^{+}$ions, we have to compare their enthalpy of formation respectively (6.7 and $9.37 \mathrm{eV}$ ). So the $\mathrm{Al}_{2} \mathrm{O}^{+}$ion is formed at a lower temperature than the $\mathrm{Al}^{+}$ion. The ionization energy of $\mathrm{Al}$ is $5.99 \mathrm{eV}$ which is lower than the ionization energy of the other monatomic species (Ar $15.76 \mathrm{eV}, \mathrm{C} 11.26 \mathrm{eV}, \mathrm{O} 13.62 \mathrm{eV}, \mathrm{N} 14.53 \mathrm{eV}$ ). Thus, the electrical neutrality is made between electrons and $\mathrm{Al}_{2} \mathrm{O}^{+}$until around $5000 \mathrm{~K}$ then the electrical neutrality is made with the aluminum ions $\mathrm{Al}^{+}$. The main chemical reactions occur at around $4200 \mathrm{~K}$. They are: the dissociation of $\mathrm{Al}_{2} \mathrm{O}$ in $\mathrm{AlO}$ and $\mathrm{Al}_{2}$ with an energy

Table 1 Vaporization temperature and sublimation temperature versus the $\mathrm{Al}$ and Air in molar percentage at $10^{5} \mathrm{~Pa}$ and thermal equilibrium at thermal equilibrium $(\theta=1)$

\begin{tabular}{llll}
\hline & $\mathrm{T}_{\text {vap }} \mathrm{Al}( \pm 3 \mathrm{~K})$ & $\mathrm{T}_{\text {sub }} \mathrm{AlN}( \pm 3 \mathrm{~K})$ & $\mathrm{T}_{\text {vap }} \mathrm{Al}_{2} \mathrm{O}_{3}( \pm 3 \mathrm{~K})$ \\
\hline $10 \%$ Air $90 \% \mathrm{Al}$ & 2767.5 & 2682.5 & 2387.5 \\
$20 \%$ Air $80 \% \mathrm{Al}$ & 2727.5 & 2687.5 & 2387.5 \\
$30 \%$ Air $70 \% \mathrm{Al}$ & 2387.5 & 2682.5 & 2502.5 \\
$40 \%$ Air $60 \% \mathrm{Al}$ & - & 2657.5 & 2532.5 \\
$50 \%$ Air $50 \% \mathrm{Al}$ & - & 2572.5 & 2522.5 \\
$60 \%$ Air $40 \% \mathrm{Al}$ & - & 2502.5 & 3712.5 \\
$70 \%$ Air $30 \% \mathrm{Al}$ & - & 2457.5 & 3757.5 \\
$80 \%$ Air $20 \% \mathrm{Al}$ & - & - & 3757.5 \\
$90 \%$ Air $10 \% \mathrm{Al}$ & - & - & 3707.5 \\
\hline
\end{tabular}


Fig. 2 a Molar fraction versus temperature of a mixture of $90 \%$ aluminum and $10 \%$ of dry standard air (in molar percentage) at $10^{5} \mathrm{~Pa}$ and at thermal equilibrium $(\theta=1)$. b Molar fraction versus temperature of a mixture of $65 \%$ aluminum and $35 \%$ of dry standard air (in molar percentage) at $10^{5} \mathrm{~Pa}$ and at thermal equilibrium $(\theta=1)$.

c Molar fraction versus temperature of a mixture of $50 \%$ aluminum and $50 \%$ of dry standard air (in molar percentage) at $10^{5} \mathrm{~Pa}$ and at thermal equilibrium $(\theta=1)$. d Molar fraction versus temperature of a mixture of $25 \%$ aluminum and $75 \%$ of dry standard air (in molar percentage) at $10^{5} \mathrm{~Pa}$ and at thermal equilibrium $(\theta=1)$. e Molar fraction versus temperature of a mixture of $10 \%$ aluminum and $90 \%$ of dry standard air (in molar percentage) at $10^{5} \mathrm{~Pa}$ and at thermal equilibrium $(\theta=1)$
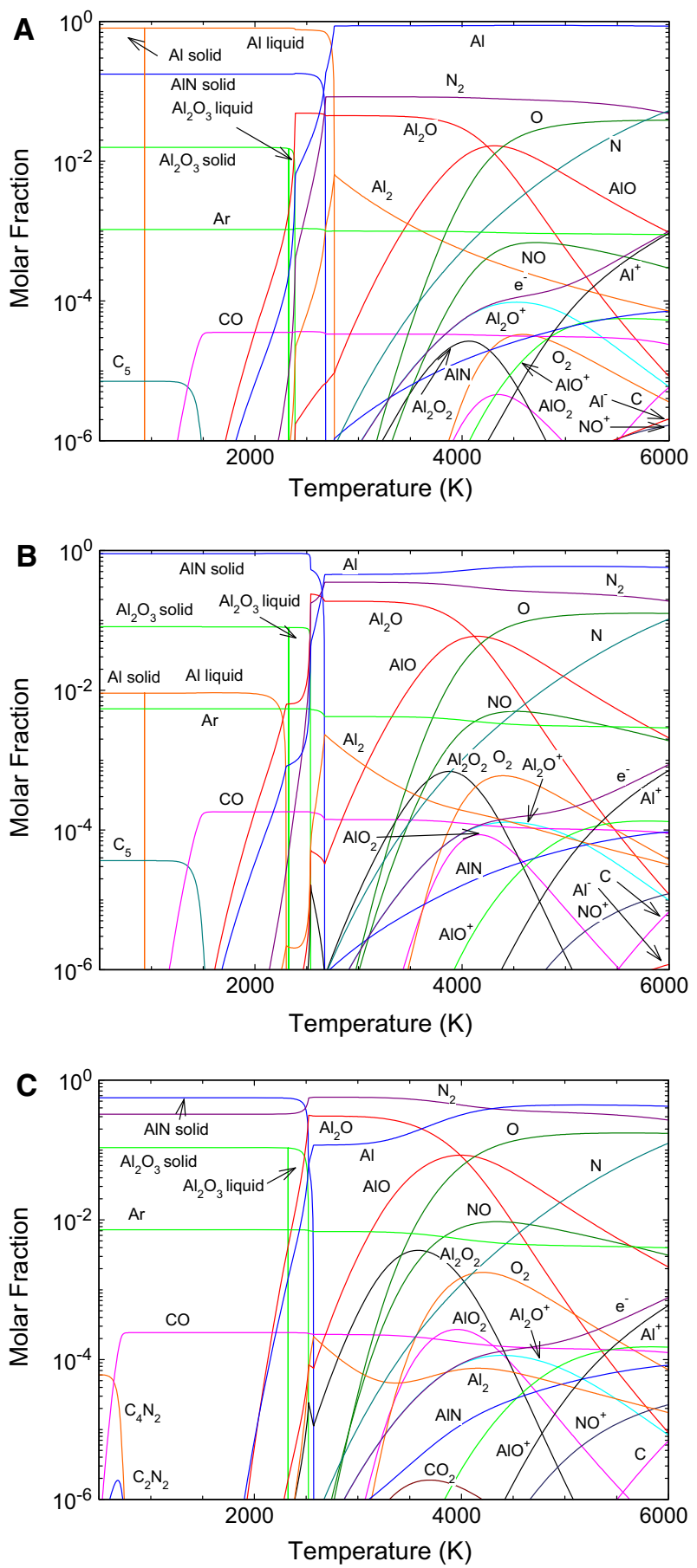
Fig. 2 continued
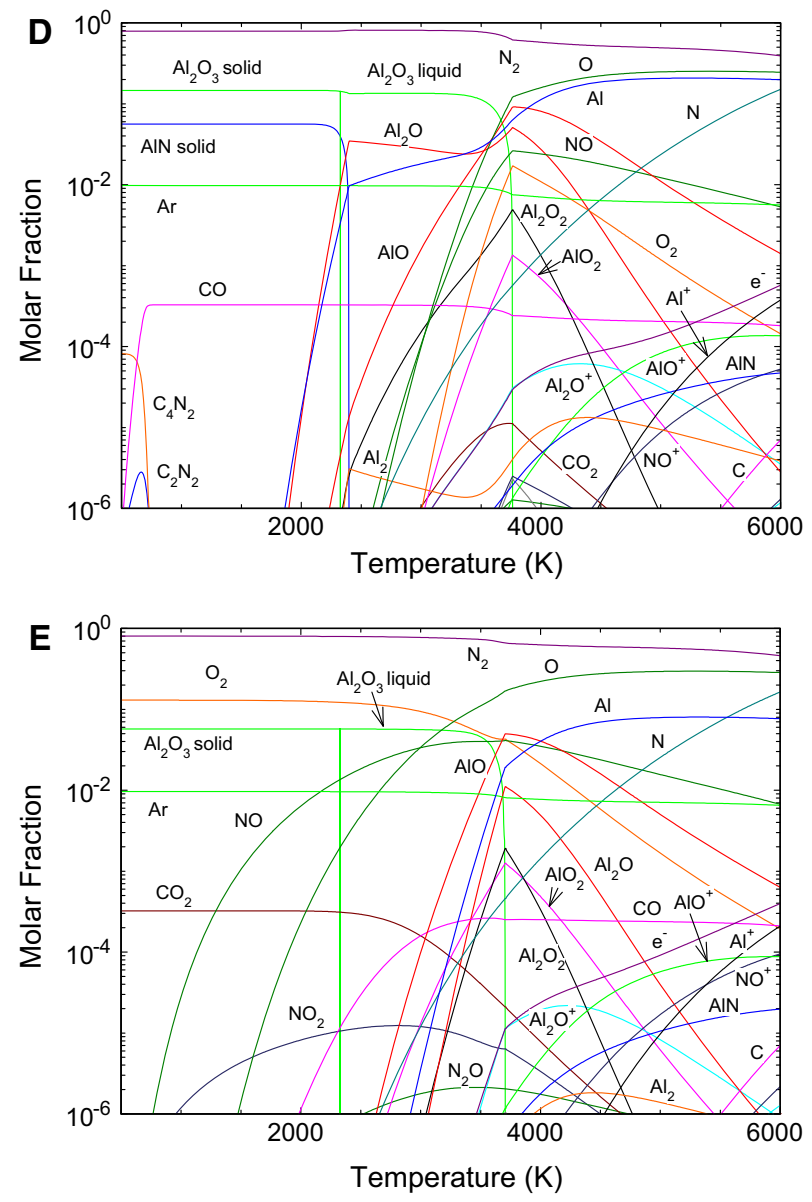

of $4.7 \mathrm{eV}$ followed by the dissociation of $\mathrm{Al}_{2} \mathrm{O}$ in $\mathrm{AlO}$ and $\mathrm{Al}$ with an energy of $5.58 \mathrm{eV}$ in parallel with the dissociation of $\mathrm{AlO}$ in $\mathrm{Al}$ and $\mathrm{O}$ with an energy of $5.25 \mathrm{eV}$.

In Fig. $2 b$ we have plotted the molar fraction of chemical species versus temperature for a mixture of pure aluminum at $65 \%$ and of dry standard air at $35 \%$ in molar percentage. The main condensed chemical species is the aluminum nitride aluminum that sublimates around $2672 \mathrm{~K}$. The second main condensed phase is aluminum oxide that is in solid phase below $2327 \mathrm{~K}$ and liquid until its vaporization around $2537 \mathrm{~K}$. The third is the aluminum in solid phase below $933 \mathrm{~K}$ and in liquid between this latter temperature and $2300 \mathrm{~K}$. Since the initial concentration of atomic $\mathrm{N}$ is higher accordingly the AlN concentration is higher. An increase in the initial quantity of oxygen also increases the concentration of $\mathrm{Al}_{2} \mathrm{O}_{3}$. The argon is the main chemical species at the lower temperature. The main gaseous species are $\mathrm{Al}, \mathrm{N}_{2}$ and $\mathrm{Al}_{2} \mathrm{O}$ after the $\mathrm{Al}_{2} \mathrm{O}_{3}$ vaporization. For the higher temperature gaseous aluminum is the main species. The electrical neutrality is made between electrons and $\mathrm{Al}_{2} \mathrm{O}^{+}$ until around $4500 \mathrm{~K}$, between electrons with $\mathrm{Al}_{2} \mathrm{O}^{+}, \mathrm{Al}^{+}, \mathrm{AlO}^{+}$between $4500 \mathrm{~K}$ and $5300 \mathrm{~K}$ and between electrons with $\mathrm{Al}^{+}$for higher temperature. We can notice that the 
concentration of $\mathrm{AlO}^{+}$increases when the air percentage increases. The main chemical reaction is made around $4200 \mathrm{~K}$ with the dissociation of $\mathrm{Al}_{2} \mathrm{O}$.

In Fig. 2c we have plotted the molar fraction of chemical species versus temperature for a mixture of pure aluminum of $50 \%$ and in dry standard air of $50 \%$ in molar percentage. The main result is that we obtain only two main condensed chemical species. They are condensed aluminum oxide that is in solid phase below $2327 \mathrm{~K}$ and liquid until its vaporization around $2522 \mathrm{~K}$ and the aluminum nitride that sublimates around $2572 \mathrm{~K}$. In fact, the number of atoms of $\mathrm{O}$ and $\mathrm{N}$ in the initial mixture is sufficient to react with condensed Al. The main gaseous chemical is Ar until $2350 \mathrm{~K}$ and when the $\mathrm{Al}_{2} \mathrm{O}_{3}$ vaporization occurs $\mathrm{Al}, \mathrm{N}_{2}$ and $\mathrm{Al}_{2} \mathrm{O}$. Nitrogen is the main chemical species until $4270 \mathrm{~K}$ and for the higher temperature gaseous aluminum is the main species. The electrical neutrality is made between electrons and $\mathrm{Al}_{2} \mathrm{O}^{+}$until around $4500 \mathrm{~K}$, between electrons with $\mathrm{Al}_{2} \mathrm{O}^{+}, \mathrm{Al}^{+}, \mathrm{AlO}^{+}$between $4930 \mathrm{~K}$ and $5450 \mathrm{~K}$ and between electrons with $\mathrm{Al}^{+}$for higher temperature. The main chemical reaction is made around $4200 \mathrm{~K}$ with the dissociation of $\mathrm{Al}_{2} \mathrm{O}$.

In Fig. 2d, we have plotted the molar fraction of chemical species versus temperature for a mixture of pure aluminum of $25 \%$ and in dry standard air of $75 \%$ in molar percentage. Unlike previously, the main condensed phase is $\mathrm{Al}_{2} \mathrm{O}_{3}$ and not the aluminum nitrate. Indeed, the number of initial atom $\mathrm{O}$ is sufficient to react with condensed $\mathrm{Al}$ and AlN to produce condensed $\mathrm{Al}_{2} \mathrm{O}_{3}$. So, they are two condensed phase aluminum oxide and the aluminum nitride. The condensed phase aluminum oxide is in solid phase below $2327 \mathrm{~K}$ and liquid until its vaporization around $3763 \mathrm{~K}$. The aluminum nitride sublimates around $2390 \mathrm{~K}$. The main chemical species is nitrogen $\mathrm{N}_{2}$ in all the considered temperature. The main gaseous chemical reaction is the dissociation of $\mathrm{NO}$ around $4850 \mathrm{~K}$. The electrical neutrality is made between electrons and $\mathrm{Al}_{2} \mathrm{O}^{+}$until around $4695 \mathrm{~K}$, between electrons with $\mathrm{AlO}^{+}$between $4695 \mathrm{~K}$ and $5580 \mathrm{~K}$ and between electrons with $\mathrm{Al}^{+}$for higher temperature.

In Fig. 2e, we have plotted the molar fraction of chemical species versus temperature for a mixture of pure aluminum of $10 \%$ and in dry standard air of $90 \%$ in molar percentage. Unlike previously, we observe only one condensed phase. It is the aluminum oxide $\mathrm{Al}_{2} \mathrm{O}_{3}$. Indeed, the number of initial atom $\mathrm{O}$ is sufficient to react with condensed $\mathrm{Al}$ and $\mathrm{AlN}$ to produce only condensed $\mathrm{Al}_{2} \mathrm{O}_{3}$. That is in solid phase below $2327 \mathrm{~K}$ and liquid until its vaporization around $3700 \mathrm{~K}$. The main chemical species is nitrogen $\mathrm{N}_{2}$ in all the considered temperature. Unlike previously we do not observe at low temperature carbon oxide $\mathrm{CO}$ but carbon dioxide $\mathrm{CO}_{2}$. As a matter of fact the number of $\mathrm{O}$ is sufficient to react with $\mathrm{CO}$ to produce $\mathrm{CO}_{2}$. The main gaseous chemical reaction is the dissociation of $\mathrm{NO}$ around $4190 \mathrm{~K}$. The electrical neutrality is made between electrons and $\mathrm{Al}_{2} \mathrm{O}^{+}$until around $4440 \mathrm{~K}$, between electrons with $\mathrm{AlO}^{+}$between $4440 \mathrm{~K}$ and $5640 \mathrm{~K}$ and between electrons with $\mathrm{Al}^{+}$for higher temperature.

Overall, it is apparent that when the proportion of air increases, the amount of the condensed chemical species $\mathrm{Al}_{2} \mathrm{O}_{3}$ and $\mathrm{AlN}$ increases. When there is enough oxygen in the mixture, the only condensed species is $\mathrm{Al}_{2} \mathrm{O}_{3}$, and $\mathrm{N}_{2}$ remains in the gaseous state. Also, when the air proportion is not sufficient in the mixture, the $\mathrm{CO}$ molecule appears; this becomes $\mathrm{CO}_{2}$ when the amount of oxygen is sufficient. With a low percentage of air and accordingly of $\mathrm{O}_{2}$, the $\mathrm{AlO}^{+}$concentration is rather low. When the initial air concentration increases, $\mathrm{AlO}^{+}$become the main contributor to electrical neutrality. When the concentration of air is low, the main chemical reactions in the gaseous phase are the dissociation of $\mathrm{Al}_{2} \mathrm{O}$ and the dissociation of $\mathrm{AlO}$. In contrast, when the concentration of air is high 
enough, the $\mathrm{Al}_{2} \mathrm{O}_{3}$ liquid vaporization temperature reaches a higher temperature. The main reaction is no longer the dissociation of $\mathrm{Al}_{2} \mathrm{O}$ dissociation but the vaporization of $\mathrm{Al}_{2} \mathrm{O}_{3}$.

The Table 1 gives the vaporization temperatures and sublimation temperatures versus the molar percentage in aluminum and air. We observe that the aluminum vaporization temperature and the aluminum nitride sublimation temperature decreases when the percentage of air increases. Unlike the aluminum oxide vaporization temperature increases when the percentage of air increases.

\section{Influence of Thermal Nonequilibrium}

In Table 2, we give the vaporization temperatures and sublimation temperature (heavy species temperature) versus the $\mathrm{Al}$ and Air proportion in molar percentage and versus thermal non-equilibrium parameter $\theta=\frac{T_{e}}{T_{h}}$ at $10^{5} \mathrm{~Pa}$. In Fig. $3 \mathrm{a}, \mathrm{b}$ we have plotted the molar fraction versus temperature of a mixture of $90 \%$ aluminum and $10 \%$ of dry standard air (in molar percentage) and a mixture of $10 \%$ aluminum and $90 \%$ of dry standard air at $10^{5} \mathrm{~Pa}$ and for thermal non equilibrium parameter $\theta=2$.

For the mixture of $90 \%$ aluminum and $10 \%$ of dry standard air, we observe that the solid phase of aluminum is mainly in chemical equilibria with monatomic species $\mathrm{Al}$; the aluminum nitride is in chemical equilibria with $\mathrm{Al}$ and nitrogen $\mathrm{N}_{2}$, the condensed phase of the aluminum oxide $\mathrm{Al}_{2} \mathrm{O}_{3}$ is in chemical equilibria with $\mathrm{Al}_{2} \mathrm{O}$ and $\mathrm{Al}$. The $\mathrm{Al}_{2} \mathrm{O}$ is in chemical equilibria with $\mathrm{AlO}$ and $\mathrm{O}$. Comparing the Figs. 2a and $3 \mathrm{a}$, we observe that the electronic concentration increases with parameter $\theta$ for a given heavy species temperature. So the ionization of $\mathrm{AlO}$ appears at lower heavy species temperature. One other characteristic for ionized chemical species is that at thermal equilibrium (Fig. 2a) the main ionized chemical species is $\mathrm{Al}_{2} \mathrm{O}^{+}$for temperatures lower than around $5000 \mathrm{~K}^{2}$ and $\mathrm{Al}^{+}$for higher temperature in the considered temperature range. Unlike in the plasma out of thermal equilibrium (Fig. 3a) the main ionic chemical species that follow one to another are $\mathrm{Al}_{2} \mathrm{O}^{+}$until $3850 \mathrm{~K}, \mathrm{AlO}^{+}$until $4725 \mathrm{~K}$, succeed $\mathrm{Al}^{+}$in our heavy species temperature range.

For the mixture of $10 \%$ aluminum and $90 \%$ of dry standard air, we observe, the condensed phase of the aluminum oxide $\mathrm{Al}_{2} \mathrm{O}_{3}$ is in chemical equilibria with $\mathrm{AlO}$, and $\mathrm{Al}$ and O. Comparing Figs. 2e and 3b, the ionization of $\mathrm{AlO}$ and $\mathrm{Al}_{2} \mathrm{O}$ appear at lower heavy

Table 2 Vaporization temperature and sublimation temperature (heavy species temperature) versus the $\mathrm{Al}$ and Air in molar percentage and versus thermal non-equilibrium parameter $\theta=T_{e} / T_{h}$. at $10^{5} \mathrm{~Pa}$

\begin{tabular}{|c|c|c|c|c|c|c|c|c|c|}
\hline & \multicolumn{3}{|c|}{$10 \%$ Air $90 \% \mathrm{Al}$} & \multicolumn{3}{|c|}{$50 \%$ Air $50 \%$ Al } & \multicolumn{3}{|c|}{$90 \%$ Air $10 \% \mathrm{Al}$} \\
\hline & $\begin{array}{l}\mathrm{T}_{\text {vap }} \mathrm{Al} \\
( \pm 3 \mathrm{~K})\end{array}$ & $\begin{array}{l}\mathrm{T}_{\text {sub }} \\
\text { AlN } \\
( \pm 3 \mathrm{~K})\end{array}$ & $\begin{array}{l}\mathrm{T}_{\text {vap }} \\
\mathrm{Al}_{2} \mathrm{O}_{3} \\
( \pm 3 \mathrm{~K})\end{array}$ & $\begin{array}{l}\mathrm{T}_{\text {vap }} \mathrm{Al} \\
( \pm 3 \mathrm{~K})\end{array}$ & $\begin{array}{l}\mathrm{T}_{\mathrm{sub}} \\
\mathrm{AlN} \\
( \pm 3 \mathrm{~K})\end{array}$ & $\begin{array}{l}\mathrm{T}_{\text {vap }} \\
\mathrm{Al}_{2} \mathrm{O}_{3} \\
( \pm 3 \mathrm{~K})\end{array}$ & $\begin{array}{l}\mathrm{T}_{\text {vap }} \mathrm{Al} \\
( \pm 3 \mathrm{~K})\end{array}$ & $\begin{array}{l}\mathrm{T}_{\text {sub }} \\
\text { AlN } \\
( \pm 3 \mathrm{~K})\end{array}$ & $\begin{array}{l}\mathrm{T}_{\text {vap }} \\
\mathrm{Al}_{2} \mathrm{O}_{3} \\
( \pm 3 \mathrm{~K})\end{array}$ \\
\hline$\theta=1$ & 2767.5 & 2682.5 & 2387.5 & - & 2572.5 & 2522.5 & - & - & 3707.5 \\
\hline$\theta=1.5$ & 2587.5 & 2577.5 & 2360.0 & - & 2497.5 & 3457.5 & - & - & 3530.0 \\
\hline$\theta=2$ & 2437.5 & 2487.5 & 2322.5 & - & 2462.5 & 3325.0 & - & - & 3347.5 \\
\hline$\theta=2.5$ & 2297.5 & 2407.5 & 2252.5 & - & 2412.5 & 3150.0 & - & - & 3155.0 \\
\hline$\theta=3$ & 2172.5 & 2330.0 & 2162.5 & - & 2342.5 & 2932.5 & - & - & 2935.0 \\
\hline
\end{tabular}


Fig. 3 a Molar fraction versus temperature of a mixture of $90 \%$ aluminum and $10 \%$ of dry standard air (in molar percentage) at $10^{5} \mathrm{~Pa}$ and for thermal non equilibrium parameter $\theta=2$. b Molar fraction versus temperature of a mixture of $10 \%$ aluminum and $90 \%$ of dry standard air (in molar percentage) at $10^{5} \mathrm{~Pa}$ and for thermal non equilibrium parameter $\theta=2$
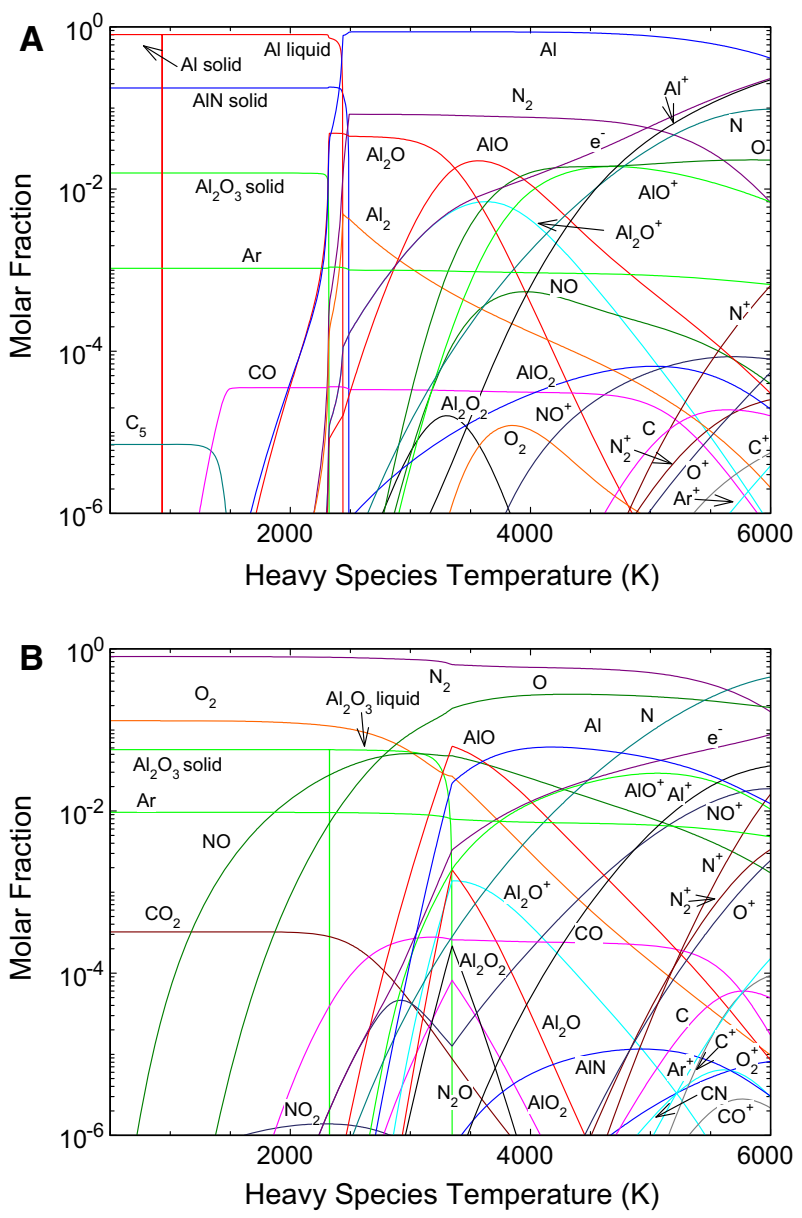

species temperature. One other characteristic for ionized chemical species is that at out thermal equilibrium the main ionized chemical species is $\mathrm{AlO}^{+}$for temperatures lower than around $5550 \mathrm{~K}$ and $\mathrm{Al}^{+}$for higher temperature in the considered temperature range. Unlike in the plasma at thermal equilibrium, the ionized chemical species follow one to another successively $\mathrm{Al}_{2} \mathrm{O}^{+}$until $4400 \mathrm{~K} \mathrm{AlO}^{+}$until $5650 \mathrm{~K}$ and $\mathrm{Al}^{+}$in our heavy species temperature range.

The energy inside the plasma is higher for a given heavy species temperature. The electronic molar fraction increases and the dissociation temperature decreases when the thermal non-equilibrium increases. The vaporization temperature and sublimation temperature (heavy species temperature) follow the same trend. As a matter of fact, the excitation temperature for monatomic species and diatomic species is assumed to be close to electronic temperature. The chemical equilibrium is made between gaseous chemical species and condensed phases. We can notice the following featured atoms and molecules: $\mathrm{Al}$ gaseous with $\mathrm{Al}$ liquid and $\mathrm{N}_{2}$ and $\mathrm{Al}$ with $\mathrm{AlN}$ solid and $\mathrm{AlO}$ with $\mathrm{Al}_{2} \mathrm{O}_{3}$ liquid. The thermal equilibrium state can be estimated from an energy balance [25]. Then from the fitting coefficients of Table 3 one can evaluate the vaporization temperatures and the 
Table 3 Fitting coefficients of temperatures versus thermal nonequilibrium parameter (* with $T=a \theta^{2}+b \theta+c ; * *$ with $\left.T=a \theta^{3}+b \theta^{2}+c \theta+d\right)$

\begin{tabular}{|c|c|c|c|c|c|c|c|}
\hline & \multicolumn{3}{|c|}{$10 \%$ Air $90 \% \mathrm{Al}$} & \multicolumn{3}{|c|}{$50 \%$ Air $50 \%$ Al } & \multirow{2}{*}{$\begin{array}{l}90 \% \text { Air } \\
10 \% \mathrm{Al} \\
\mathrm{T}_{\text {vap }} \mathrm{Al}_{2} \mathrm{O}_{3} *\end{array}$} \\
\hline & $\mathrm{T}_{\text {vap }} \mathrm{Al} \mathrm{l}^{*}$ & $\mathrm{~T}_{\mathrm{sub}} \mathrm{AlN} *$ & $\mathrm{~T}_{\text {vap }} \mathrm{Al}_{2} \mathrm{O}_{3} *$ & $\begin{array}{l}\mathrm{T}_{\text {sub }} \\
\text { AlN** }\end{array}$ & $\begin{array}{l}\mathrm{T}_{\text {vap }} \mathrm{Al}_{2} \mathrm{O}_{3} * \\
\boldsymbol{\theta}<1.4\end{array}$ & $\begin{array}{l}\mathrm{T}_{\text {vap }} \mathrm{Al}_{2} \mathrm{O}_{3} * \\
\boldsymbol{\theta} \geq 1.4\end{array}$ & \\
\hline$a$ & 34.3 & 18.6 & -45.0 & -40 & -62.5 & -90.8 & -27.1 \\
\hline$b$ & -433 & -249 & 68.5 & 239 & 86.3 & 61.2 & -275 \\
\hline$c$ & 31.65 & 2912 & 2363 & -549 & 2499 & 3566 & 4008 \\
\hline$d$ & & & & 2923 & & & \\
\hline
\end{tabular}

sublimation temperatures that can be used in a CFD code or for resolution of the Stefan problem [26].

\section{Influence of the Pressure}

In Table 4, we give the vaporization temperatures and sublimation temperature versus the $\mathrm{Al}$ and air proportion in molar percentage and versus the pressure $\left(10^{5}-30 \times 10^{5} \mathrm{~Pa}\right)$ at thermal equilibrium $(\theta=1)$. In Fig. $4 a$, b, we have plotted molar fractions versus temperature of a mixture of $90 \%$ aluminum and $10 \%$ of dry standard air and of $10 \%$ aluminum and $90 \%$ of dry standard air (in molar percentage) at thermal equilibrium and for a pressure of $15 \times 10^{5} \mathrm{~Pa}$.

About the presence of condensed phase the same conclusion can be made than at $10^{5} \mathrm{~Pa}$ (§II). For the mixture of $90 \%$ aluminum and $10 \%$ of dry standard air, comparing Figs. $4 \mathrm{a}$ and $2 \mathrm{a}$, we observe that the vaporization temperatures and sublimation temperature are higher for higher pressures. The dissociation of $\mathrm{Al}_{2} \mathrm{O}$ appearing about $4250 \mathrm{~K}$ at $10^{5} \mathrm{~Pa}$ appears around $5100 \mathrm{~K}$ for a pressure of $15 \times 10^{5} \mathrm{~Pa}$. The same behavior can be observed for the ionization the neutrality between electrons and $\mathrm{Al}_{2} \mathrm{O}^{+}$is made for higher temperature.

For the mixture of $10 \%$ aluminum and $90 \%$ of dry standard air, comparing Figs. 2e and $4 \mathrm{~b}$, we observed that the vaporization temperature of the aluminum oxide increases.

Table 4 Vaporization temperature and sublimation temperature versus the $\mathrm{Al}$ and Air in molar percentage and versus pressures at thermal equilibrium $(\theta=1)$

\begin{tabular}{|c|c|c|c|c|c|c|c|c|c|}
\hline & \multicolumn{3}{|c|}{$10 \%$ Air $90 \% \mathrm{Al}$} & \multicolumn{3}{|c|}{$50 \%$ Air $50 \%$ Al } & \multicolumn{3}{|c|}{$90 \%$ Air $10 \%$ Al } \\
\hline & $\begin{array}{l}\mathrm{T}_{\text {vap }} \mathrm{Al} \\
( \pm 3 \mathrm{~K})\end{array}$ & $\begin{array}{l}\mathrm{T}_{\text {sub }} \\
\text { AlN } \\
( \pm 3 \mathrm{~K})\end{array}$ & $\begin{array}{l}\mathrm{T}_{\text {vap }} \\
\mathrm{Al}_{2} \mathrm{O}_{3} \\
( \pm 3 \mathrm{~K})\end{array}$ & $\begin{array}{l}\mathrm{T}_{\mathrm{vap}} \mathrm{Al} \\
( \pm 3 \mathrm{~K})\end{array}$ & $\begin{array}{l}T_{\text {sub }} \\
\text { AlN } \\
( \pm 3 \mathrm{~K})\end{array}$ & $\begin{array}{l}\mathrm{T}_{\text {vap }} \\
\mathrm{Al}_{2} \mathrm{O}_{3} \\
( \pm 3 \mathrm{~K})\end{array}$ & $\begin{array}{l}\mathrm{T}_{\text {vap }} \mathrm{Al} \\
( \pm 3 \mathrm{~K})\end{array}$ & $\begin{array}{l}T_{\text {sub }} \\
\text { AlN } \\
( \pm 3 \mathrm{~K})\end{array}$ & $\begin{array}{l}\mathrm{T}_{\text {vap }} \\
\mathrm{Al}_{2} \mathrm{O}_{3} \\
( \pm 3 \mathrm{~K})\end{array}$ \\
\hline $\mathrm{P}=110^{5} \mathrm{~Pa}$ & 2767.5 & 2682.5 & 2387.5 & - & 2572.5 & 2522.5 & - & - & 3707.5 \\
\hline $\mathrm{P}=510^{5} \mathrm{~Pa}$ & 3162.5 & 2895.0 & 2665.0 & - & 2800.0 & 2735.0 & - & - & 4040.0 \\
\hline $\mathrm{P}=1010^{5} \mathrm{~Pa}$ & 3372.5 & 2985.0 & 2805.0 & - & 2915.0 & 2840.0 & - & - & 4205.0 \\
\hline $\mathrm{P}=1510^{5} \mathrm{~Pa}$ & 3512.5 & 3037.5 & 2885.0 & - & 2985.0 & 2905.0 & - & - & 4310.0 \\
\hline $\mathrm{P}=2010^{5} \mathrm{~Pa}$ & 3617.5 & 3075.0 & 2945.0 & - & 3040.0 & 2952.5 & - & - & 4387.5 \\
\hline $\mathrm{P}=2510^{5} \mathrm{~Pa}$ & 3702.5 & 3105.0 & 2992.5 & - & 3080.0 & 2992.5 & - & - & 4450.0 \\
\hline $\mathrm{P}=3010^{5} \mathrm{~Pa}$ & 3777.5 & 3130.0 & 3030.0 & - & 3115.0 & 3022.5 & - & - & 4500.0 \\
\hline
\end{tabular}



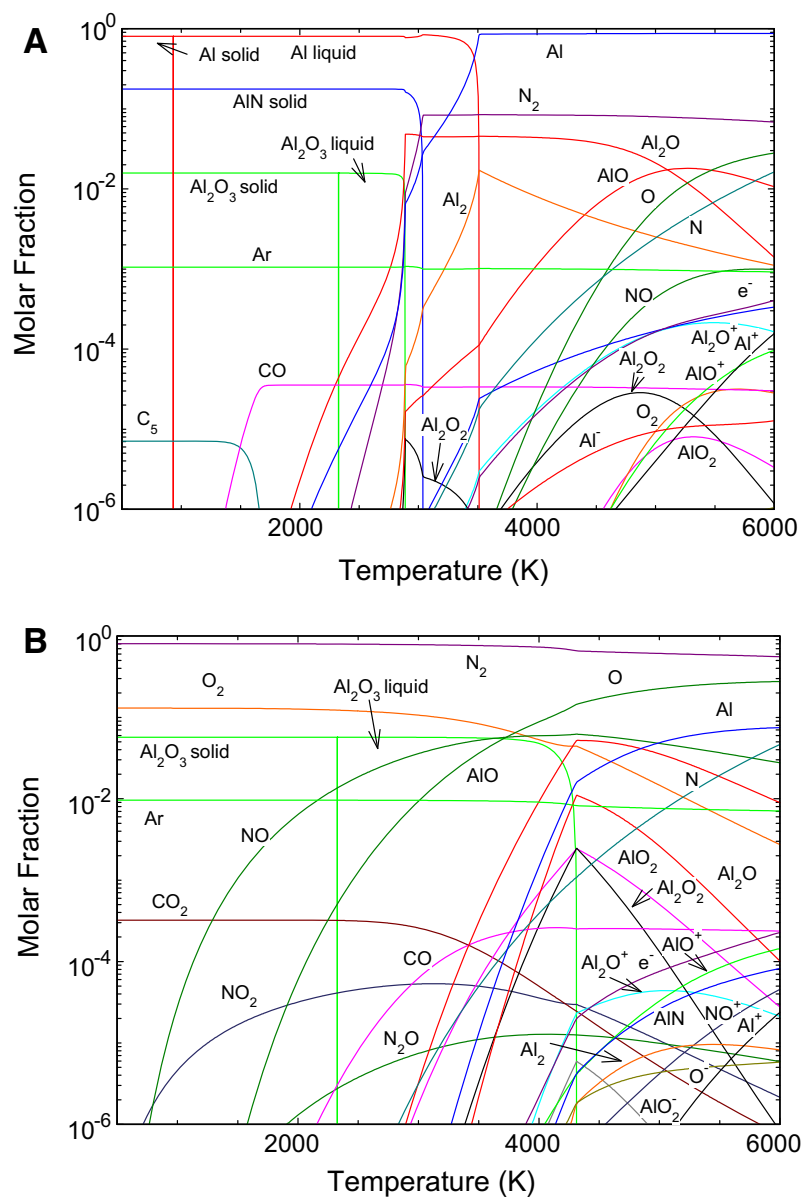

Fig. 4 a Molar fraction versus temperature of a mixture of $90 \%$ aluminum and $10 \%$ of dry standard air (in molar percentage) at thermal equilibrium $(\theta=1)$ and for a pressure of 15 bars. b Molar fraction versus temperature of a mixture of $10 \%$ aluminum and $90 \%$ of dry standard air (in molar percentage) at thermal equilibrium $(\theta=1)$. and for a pressure of 15 bars

The dissociation temperature increases consequently the electrical neutrality is made between electrons and $\mathrm{AlO}^{+}$for higher temperatures. When the pressure increases, the vaporization temperature increases and the condensed phase can appear at higher temperatures. Indeed, Le Chatelier's principle demonstrates that an increase in system pressure causes the chemical reactions to shift to the side with the fewer moles of gas [27]. So for example the reaction: $\mathrm{Al}_{2} \mathrm{O} \rightarrow \mathrm{AlO}+\mathrm{Al}$ is shifted to higher temperatures when the pressure increases.

\section{Conclusion}

The molar fraction in a plasma at and out of thermal equilibrium, with three temperatures taken into account $\left(T_{r o t}=T_{h} ; T_{v i b}=\sqrt{\theta} T_{h} ; T_{e x}=T_{e}=\theta T_{h}\right)$, consisting of air and 
aluminum for several percentages in the temperature range of 500-6000 K have been calculated with the Gibbs free energy method. The condensed phases of AlN (sol), Al (liq,sol) and $\mathrm{Al}_{2} \mathrm{O}_{3}$ (liq,sol) have been taken into account. Then the vaporization temperatures of $\mathrm{Al}_{2} \mathrm{O}_{3}$ and $\mathrm{Al}$ and the sublimation temperature of $\mathrm{AlN}$ have been calculated with an accuracy of $\pm 3 \mathrm{~K}$.

We have shown that the air percentage plays a major role to create these condensed phases: at high proportion of air we get one condensed chemical species $\left(\mathrm{Al}_{2} \mathrm{O}_{3}\right)$ unlike at the low proportion of air where we get three condensed phases $\left(\mathrm{Al}, \mathrm{AlN}, \mathrm{Al}_{2} \mathrm{O}_{3}\right)$. Concerning the pressure and the thermal non equilibrium, they play the major role on the value of the vaporization temperatures and on the sublimation temperature. The values of these considered temperatures increases when the pressure increases. We have clarified the role play on the vaporization temperatures and the sublimation temperature by the non-thermal equilibrium. We have shown that the variation in the vaporization and sublimation temperatures can reach $800 \mathrm{~K}$. This leads to large changes in the ablation processes that occur, for example in the cathodic arc root [6]. We have discussed the gaseous chemical species in chemical equilibrium with the condensed phase. Theoretical results can explain several behavior of set up when the condensed phase is created notably by electrical conductivity that are different one to another condensed phases [28] appearing after extinguishing of the electric arc or the plasma. The chemical species leading to the electrical neutrality have been studied during the plasma phase. One featuring chemical species is the diatomic AlO that can be used to evaluate the temperatures inside the plasma and of which concentration depends on the pressure and air proportion. Notably, the chemical equilibria between $\mathrm{Al}_{2} \mathrm{O}_{3}$ (sol) and $\mathrm{AlO} \mathrm{Al}$ and $\mathrm{O}$. We can notice that the presence of $\mathrm{CO}_{2}$ in standard air can be neglected since the purity of aluminum and the humidity cannot reach such level of purity. The real mixture is contaminated by pollutants originating from the aluminum. We have shown that for a given mixture of air and aluminum the same condensed chemical species appearing at $10^{5} \mathrm{~Pa}$. appear at higher pressures at higher temperatures.

\section{References}

1. André $P$ (1995) Partition functions and concentrations in plasmas out of thermal equilibrium. IEEE Trans Plasma Sci 23(3):453

2. André P, Koalaga Z (2010) Composition of a thermal plasma formed from PTFE with copper in nonoxidant atmosphere Part I Definition of a test case with the SF6. High Temp Mater Process Int Q HighTechnol Plasma Process 14(3):285-294

3. André P, Lefort A (1998) The influence of thermal disequilibrium on a plasma consisting of insulator vapours. J Phys D Appl Phys 31(6):717

4. André P, Barinov Y, Faure G, Shkol'nik S (2011) Modelling radiation spectrum of a discharge with two liquid non-metallic (tap-water) electrodes in air at atmospheric pressure. J Phys D Appl Phys 44(37):375203

5. André P, Bussière W, Coulbois A, Gelet J, Rochette D (2016) Modelling of electrical conductivity of a silver plasma at low temperature. Plasma Sci Technol (accepted)

6. Aubreton J, Elchinger M, André P (2013) Influence of Partition Function and Intercation Potential on Transport Properties of Thermal Plasmas. Plasma Chem Plasma Process 33(1):367-399

7. Augeard A, Desprez P, Singo T, Abbaoui M (2015) Observation par caméra rapide des spots cathodiques dans l'air au niveau du CID des éléments batterie lithium-ion. JITIPEE 1:1-9

8. Capitelli M, Molinari E (1970) Problems of determination of high temperature thermodynamic properties of rare gases with application to mixtures. J Plasma Phys 4(2):335-355

9. Chase MW (1998) NIST-JANAF thermochemical tables (Journal of physical and chemical reference data monograph No. 9), 4th edn. American Chemical Society and the American Institute of Physics for NIST (National Institute of Standards and Technology) 
10. Drellishak K, Aeschliman D, Cambel Ali Bulent (1965) Partition functions and thermodynamic properties of nitrogen and oxygen plasmas. Phys Fluids 8(9):1590

11. Dricot F, Reher H (1994) Survey of arc tracking on aerospace cables and wires. IEEE Trans Dielectr Electr Insul 1(5):896-903

12. Fridman A, Kennedy L (2004) Plasma physics and engineering. Taylor \& Francis, New York

13. Giordano D, Capitelli M (2002) Nonuniqueness of the two temperature Saha equation and related consideration. Phys Rev E 65:016401

14. Giordano D, Capitelli M (1995) Two-temperature Saha Equation a misunderstood problem. J Thermophys Heat Transfer 9(4):803

15. Gordon S, McBride B (1976) Computer Program for calculation of complex chemical equilibrium compositions, Rocket Performance Incident and reflected shocks and chapman jouguet detonation. NASA

16. Haynes W, Lide D, Bruno T (2012) CRC Handbook of chemistry and physics, 93rd edn. CRC Press, Taylor \& Francis Group

17. Lefort A, Abbaoui M (2012) Theory about arc root: a review. IOP Cof Ser Mater Sci Eng 29:012006

18. Lesaint P, Touzani R (1989) Approximation of the heat equation in a variable doamin with application to the Stefan problem. SIAM J Numer Anal 26(2):366-379

19. Murphy AB (2015) Why the arc and its interactions with the electrodes are important in predictive modelling of arc welding. Plasma Phys Technol 2(3):233-240

20. Murphy A, Tanaka M, Yamamoto K, Sato T, Lowke J (2009) Modelling of thermal plasmas for arc welding: the role of the shielding gas properties and of metal vapour. J Phys D Appl Phys 42:194006

21. NIST. (s.d.). Récupéré sur NIST Atomic Spectra Database Levels Data: http://physics.nist.gov/ PhysRefData/ASD/levels_form.html

22. Raja LL, Varghese P, Wilson D (1997) Modeling of the electrothermal ignitor metal vapor plasma for electrothermal-chemical guns. IEEE Trans Magn 33(1):316-321

23. Rochette D, Bussière W, André P (2004) Composition, enthalpy, and vaporization temperature calculation of $\mathrm{Ag}-\mathrm{SiO}_{2}$ plasmas with air in the temperature range from 1000 to $6000 \mathrm{~K}$ and for pressure included between 1 and 50 bars. Plasma Chem Plasma Process 24(3):475-492

24. Rong M, Wang W, Yan J, Murphy A, Spencer J (2011) Thermophysical properties of nitrogen plasmas under thermal equilibrium and non-equilibrium conditions. Phys Plasmas 18:113502. doi:10.1063/1. 3657426

25. Rossignol J, Abbaoui M, Clain S (2000) Numerical modelling of thermal ablation phenomena due to a cathodic spot. J Phys D Appl Phys 33:2079-2086

26. Staack D, Bakhtier F, Gutsol A, Fridman A (2005) Characterization of a dc atmospheric pressure normal glow discharge. Plasma Sour Sci Technol 14(4):700-711

27. Zhao TL, Xu Y, Song YH, Li XS, Liu JL, Liu JB, Zhu AM (2013) Determination of vibrational and rotational temperatures in a gliding arc discharge by using overlapped molecular emission spectra. J Phys D Appl Phys 46(34):345201

28. Wade K, Banister A (1975) The chemistry of aluminium, gallium, indium and thallium. Pergamon Press, Oxford 